\title{
Aspecto bioquímico em fígados de Rana catesbeiana (SHAW, 1802) submetida a diferentes dietas
}

\author{
Marcio Hipólito \\ Apta-SAA-SP. IQ-Unesp. \\ Araraquara - SP [Brasil] \\ hipólito@biologico.sp.gov.br \\ Oswaldo Pinto Ribeiro Filho \\ UFV. \\ Viçosa - MG [Brasil] \\ Erna Elisabeth Bach \\ IQ-Unesp; Uninove. \\ São Paulo - SP [Brasil] \\ ernabach@uol.com.br
}

Com o objetivo de adequar uma dieta, rãs-touro (Rana catesbeiana) foram submetidas a diferentes dietas e analisadas, posteriormente, as substâncias bioquímicas de seu fígado. As dietas experimentais, com base em alimentos contendo proteínas/lipídios, apresentaram $40 \%$ de proteína bruta (PB) e foram suplementadas com diferentes quantidades de óleo de soja (OS) (tratamento 1: 6\% de OS; tratamento 2: $9 \%$ OS, e tratamento 3: $12 \%$ OS). A dietacontrole foi um alimento comercial com $40 \%$ PB e $4 \%$ de extrato etéreo. Os animais foram avaliados depois de 30, 60 e 90 dias do início da alimentação. Retiram-se extratos do fígado e quantificados em relação às proteínas, aos fenóis, à enzima peroxidase e ao glicogênio. Os animais que tiveram maior concentração de proteínas e glicogênio foram submetidos à alimentação com $9 \%$ de OS e $40 \%$ $\mathrm{PB}$. Os mesmos animais apresentaram decréscimo da atividade de peroxidase e de concentração de fenóis, que podem ser os indicadores necessários para demonstrar a melhor dieta.

Palavras-chave: Fígado. Nutrição. Rã-touro.

Rana catesbeiana. 


\section{Introdução}

A rã-touro (Rana catesbeiana), originária da América do Norte, é criada no Brasil em ranários construídos com diferentes tecnologias. Há desde sistemas fechados, como anfigranja e estufa, até outros com uso de água circulante aquecida. Todos têm por base proporcionar temperaturas constantes, para aumento da produção não só de animais, mas também de carne para abate (FONTANELLO et al., 1988). Esse aumento na produtividade é decorrente da moderna tecnologia aplicada nas práticas de criação e do uso de medidas profiláticas e sanitárias (HIPOLITO, 1999).

A alimentação da rã-touro em cativeiro, nos sistemas semi-secos, tem sido feita com ração industrial peletizada, colocada em cochos vibratórios, ou com indutores biológicos. Atualmente, a maioria das fórmulas comerciais de rações utilizadas na ranicultura, ou é destinada a peixes, ou dela derivada, não existindo formulações exclusivas para a rã-touro (ACADEMIA BRASILEIRA DE ESTUDOS TÉCNICOS EM RANICULTURA, 2001), o que deve interferir no processo nutricional, acarretando tanto deficiência protéica quanto lesões hepáticas (BROWN JUNIOR, 1964). Dados experimentais demonstraram a exigência de 40 a $45 \%$ de proteína bruta na ração, entre vários parâmetros estudados, mas nada relacionado diretamente com o estado hepático (HIPOLITO, 2003).

Como tem aumentado a presença de rãstouro com lesões hepáticas, o objetivo deste trabalho foi avaliar, por meio de análises bioquímicas, os fígados de rãs submetidas a diferentes dietas experimentais. Os fígados foram analisados em relação à quantidade de proteínas e fenóis totais, à atividade da enzima peroxidase e à concentração do glicogênio. Os resultados, depois de comparados com outros esquemas nutricionais e diferentes fórmulas, podem ser usados como indicadores de desenvolvimento nutricional e ainda apontar a presença de estresse oxidativo e de degeneração celular, em decorrência de alterações metabólicas geradas por processos degenerativos ou tóxicos.

\section{Material e método}

O experimento do desenvolvimento animal foi conduzido nas dependências do Ranário Experimental da Universidade Federal de Viçosa (UFV) e feitas as análises bioquímicas no Instituto Biológico de São Paulo (SP).

\subsection{Animais}

O Ranário Experimental da UFV montou um procedimento-padrão, baseado em Ribeiro Filho (1999), no qual foram utilizados mil animais, machos e fêmeas, com peso médio inicial de 50 gramas (g), acondicionados em baias, com dimensões de $5 \times 4,5$ metros (m), totalizando uma área de 22,5 metros quadrados $\left(\mathrm{m}^{2}\right)$, com abrigos, piscina e cochos. Utilizou-se um delineamento inteiramente casualizado, com três tratamentos e repetições, em esquema fatorial 3 x 1 x 3 (três níveis de energia $x$ um de proteína $x$ três períodos de avaliação), com 30 animais por repetição, avaliados três vezes a cada 30 dias, isto é, aos 30, 60 e 90 dias do experimento.

A ração experimental foi preparada, observando-se a análise centesimal e a composição química das dietas, constituídas de $40 \%$ de proteína bruta e óleo de soja, nas concentrações de 6,9 e $12 \%$. No grupo-controle, foi utilizada ração comercial, destinada a peixe carnívoro, com $40 \%$ de proteína bruta e $4 \%$ de extrato etéreo (Quadro 1).

As rações experimentais foram preparadas conforme a composição (Tabela 1).

\subsection{Extração de proteína}

Um grama de fígado de cada tratamento foi triturado em almofariz gelado (4 graus Celsius $\left[{ }^{\circ} \mathrm{C}\right]$ ) contendo nitrogênio líquido e 


\begin{tabular}{|c|c|c|c|}
\hline Tratamento & Composição & Tempo para avaliação & Grupos \\
\hline T-controle & $\begin{array}{c}40 \% \text { de proteína bruta e 4\% } \\
\text { de extrato etéreo }\end{array}$ & $30,60,90$ dias & $1 \mathrm{~T}, 2 \mathrm{~T}, 3 \mathrm{~T}$ \\
\hline T1 & $40 \%$ de proteína bruta e 6\% de óleo de soja & $30,60,90$ dias & $1,2,3$ \\
\hline T2 & $40 \%$ de proteína bruta e 9\% de óleo de soja & $30,60,90$ dias & $4,5,6$ \\
\hline T3 & $40 \%$ de proteína bruta e 12\% de óleo de soja & $30,60,90$ dias & $7,8,9$ \\
\hline
\end{tabular}

Quadro 1: Relação dos tratamentos e do tempo para avaliações

Fonte: Os autores.

\begin{tabular}{c|c|c|c|c}
\hline Composição calculada & Ração T1 & Ração T2 & Ração T3 & $\begin{array}{c}\text { Ração-controle } \\
\text { (níveis de garantia) }\end{array}$ \\
\hline Proteína bruta* (\%) & 40 & 40 & 40 & 42 (mínimo) \\
\hline $\begin{array}{c}\text { Energia metabólica ver- } \\
\text { dadeira** (Kcal/kg) }\end{array}$ & 2.950 & 3.050 & 3.150 & \\
\hline Cálcio (\%) & 3 & 3 & 3 & 3 (máximo) \\
\hline Fósforo disponível (\%) & 1,5 & 1,5 & 1,5 & 1,3 (mínimo) \\
\hline Óleo de soja (\%) & 6 & 9 & 12 & 4 (mínimo) \\
\hline Extrato etéreo (\%) & - & - & - & 10 (máximo) \\
\hline Umidade (\%) & - & - & - & 15 (máximo) \\
\hline Matéria mineral (\%) & - & - & - & 4 (máximo) \\
\hline Matéria fibrosa (\%) & - & - & - &
\end{tabular}

Tabela 1: Composição das rações experimentais e da comercial (controle).

Obs.: * proteína bruta (milho, farelo de soja, farinha de peixe); quilocaloria por quilo (Kcal $/ \mathrm{kg})$.

Fonte: Os autores.

acetona. O homogenato foi filtrado em papel de filtro (Whatmann n. 42) e lavado com acetona gelada. O pó cetônico foi seco e dissolvido em tampão fosfato 0,1 Molar (mol) $\mathrm{pH}=7 \mathrm{com}$ 0,25\% de ácido cítrico, e o extrato, filtrado em papel de filtro e estocado a $4^{\circ} \mathrm{C}$ até a realização das análises.

\subsection{Quantificaçã̃o de proteínas e fenóis}

O conteúdo protéico foi determinado, de acordo com o método de Lowry e colaboradores (1951), usando-se soro albumina bovina (SAB) como padrão, e o total de fenóis, definido pelo método de Folin-Ciocalteau, utilizando-se ácido clorogênico como padrão (SWAIN; HILLIS, 1959).

\subsection{Atividade da enzima peroxidase}

A atividade da peroxidase foi determinada, medindo-se a variação de absorbância do tetraguaiacol, formado na reação enzimática em espectrofotômetro computadorizado Beckman DU 650, com comprimento de onda de 470 nanômetros (nm). Nessa determinação, foram usados 0,05 mililitros (mL) do extrato do fígado da rã em 2,95 mL da solução de guaiacol, $0,9 \mu \mathrm{mol} \mathrm{L}{ }^{-1}$ e $0,36 \mu \mathrm{mol} \mathrm{L} \mathrm{L}^{-1}$ da solução de peróxido de hidrogênio em tampão fosfato $0,1 \mathrm{~mol}$ $\mathrm{L}^{-1}(\mathrm{pH} 7,0)$, a $37^{\circ} \mathrm{C}$, segundo Moerschbacher e colaboradores (1986). A absorbância foi lida em dois minutos, e a atividade específica, expressa como nKat/mgSAB/1g de fígado (SOUTHERTON; DEVERALL, 1990). 


\subsection{Glicogênio}

A dosagem foi baseada na reação do ácido 3,5 dinitrosalicílico (DNS) com açúcares redutores, segundo Miller (1959). Para a extração do glicogênio, foi pesado $1 \mathrm{~g}$ de fígado, colocado em tubo de vidro e cortado com tesoura, sendo adicionados 2,25 $\mathrm{mL}$ de hidróxido de sódio a 30\% e fervidos, por uma hora, em banho-maria. Em seguida, adicionaram-se 2,625 mL de álcool etílico $95 \%$ e $0,375 \mathrm{~mL}$ de solução saturada de sulfato de sódio, resfriado por cinco minutos e agitado. Na seqüência, transferiu-se $1,5 \mathrm{~mL}$ desse preparado para outro tubo, sendo centrifugado, por três minutos, a 1.000 rotações por minuto (rpm). O sobrenadante foi descartado e o precipitado ressuspendido com $1 \mathrm{~mL}$ de água destilada, acrescentado 1,5 mL de álcool etílico. Depois de permanecer em repouso por três minutos, a suspensão foi novamente centrifugada nas mesmas condições. Para a hidrólise ácida do glicogênio, o sobrenadante foi descartado, sendo adicionado 1,25 mL de ácido clorídrico $5 \mathrm{~mol}$, fervido por 30 minutos e transferido para outro tubo, e sua acidez, neutralizada com hidróxido de sódio $5 \mathrm{~mol}$, completado, com água, até o volume de 12,5 mL.

Para a leitura, $2,5 \mathrm{~mL}$ do preparado neutralizado foram acrescidos com $1 \mathrm{~mL}$ da solução de DNS (1 g de ácido 3,5 dinitrosalicílico; $20 \mathrm{~mL}$ de hidróxido de sódio 2 mol; 30 g de tartarato de sódio e potássio; $100 \mathrm{~mL}$ de água), fervido por cinco minutos. Em seguida, foram feitos o resfriamento e a leitura $(540 \mathrm{~nm})$ em espectrofotômetro.

\section{Resultados}

Conforme enumerações a seguir.

\subsection{Animais}

Após o abate, todos os animais apresentaram, visualmente, fígados normais. Alguns animais do grupo-controle e outros que foram tratados com dieta envolvendo $6 \%$ de óleo de soja, e apresentaram alterações na sua coloração, com um leve escurecimento e algumas lesões hepáticas vistas por meio de análises histológicas. Observaram-se essas lesões hepáticas como evidências de deficiência protéica com vacuolização dos hepatócitos, apresentando um aspecto rendilhado decorrente da falta de deposição protéica no seu citoplasma. A não-deposição de proteínas pode estar relacionada, entre várias causas, com a qualidade da proteína, seu nãoaproveitamento pelo organismo, ou alterações metabólicas hepáticas.

\subsection{Quantificação de proteínas e glicogênio}

Os animais do grupo-controle (1T, 2T, 3T) apresentaram aumento de proteína relacionado ao tempo de desenvolvimento, enquanto os animais submetidos à dieta com óleo de soja tiveram comportamento diferente. Os submetidos a dietas com 6 e $9 \%$ de óleo de soja demonstraram comportamentos semelhantes nos 30 e 60 dias de desenvolvimento, com aumento na concentração de proteínas; já aos 90 dias, constatou-se diminuição. Para os animais submetidos à dieta com $12 \%$ de óleo de soja, ocorreu diminuição na concentração de proteínas, de acordo com o período de desenvolvimento (Gráfico 1).

A formação de glicogênio se deu em todos os tratamentos, com maior incidência nos grupos que se submeteram à dieta suplementada com óleo de soja. No tratamento com $9 \%$ de óleo de soja, no grupo com 90 dias, observou-se que, em relação aos outros tratamentos, houve maior concentração (Gráfico 1). Diante disso, foi possível correlacionar resultados de proteína e glicogênio, demonstrando que, em $9 \%$, o resultado foi superior ao dos tratamentos com 6 e 12\% de óleo de soja na dieta.

\subsection{Quantificação de fenóis}

Os subgrupos 2T e 3T do grupo-controle, que receberam dieta com $4 \%$ de extrato etéreo, 


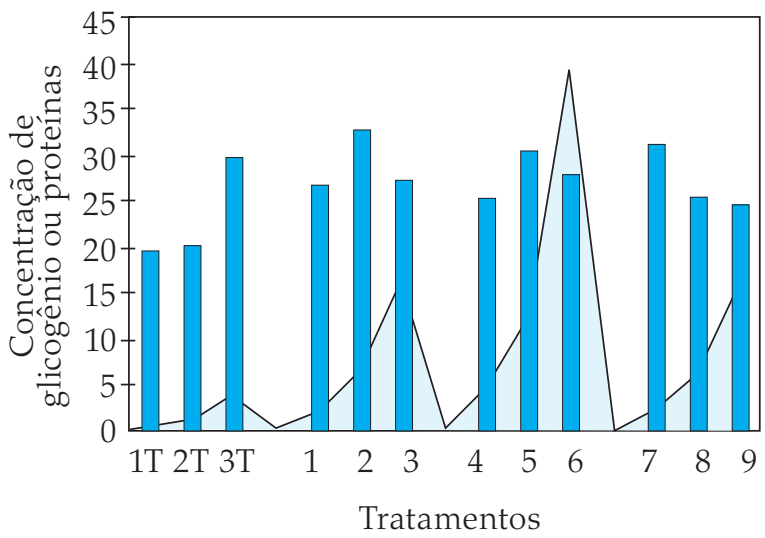

Glicogênio

Proteína

Grófico 1: Concentração de glicogênio (g glicose/Kg de fígado) e proteínas (mg $\mathrm{SAB} / \mathrm{g}$ fígado) presentes nos fígados das rãs submetidas a diferentes dietas durante o seu desenvolvimento

Fonte: Os autores.

apresentaram valores de ácido clorogênico superiores aos dos animais que receberam dieta com óleo de soja. No subgrupo 1T, entretanto, verificou-se quantidade idêntica à do grupo 1, que recebeu $6 \%$ de óleo de soja. Para os animais que receberam 9 e $12 \%$ de óleo de soja, a quantidade foi menor (Gráfico 2).

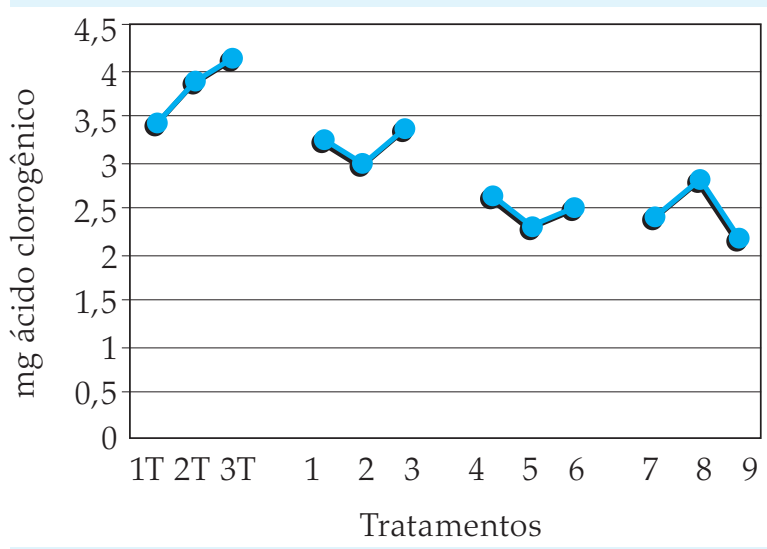

Grófico 2: Quantificação de fenóis (mg de ócido clorogênico/g de fígado) presentes nos fígados de rãs submetidas a diferentes dietas

Fonte: Os autores.

\subsection{ATtividade da peroxidase}

O grupo-controle apresentou aumento da atividade da peroxidase aos 60 dias da dieta (2T), com decréscimo aos 90 dias (3T). Já os animais submetidos à dieta experimental de 6\% de óleo de soja, aos 30 dias (grupo 1), apresentaram uma atividade menor que a do grupo-controle (1T), enquanto, aos 90 dias, o grupo 2 registrou um aumento na atividade na comparação com o grupo-controle. Os animais dos grupos de 4 a 9, correspondentes a dietas com 9 e 12\% de óleo de soja, diminuíram a atividade (Gráfico 3).

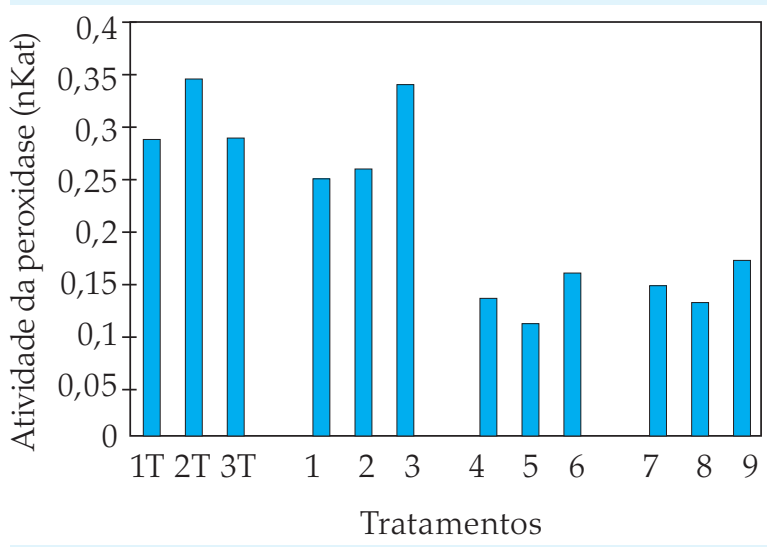

Gráfico 3: Atividade da peroxidase (nKat/ $\mathrm{mgSAB} / \mathrm{lg}$ de fígado) em fígados de rãs submetidas a diferentes dietas

Fonte: Os autores.

\section{Discussão}

Atualmente, a maioria das fórmulas comerciais de rações utilizadas na ranicultura é destinada a peixes ou suas derivadas, não existindo uma formulação exclusiva para a rã-touro, em suas várias etapas de desenvolvimento. A falta de um produto específico pode interferir no processo nutricional das rãs, visto que, ao completar sua metamorfose, passam a ter um sistema digestivo próprio para carnívoros, ou seja, intestinos curtos. Como essas formulações tendem a suprir mais as características de animais onívoros, as rãs não conseguem adaptarse a esse tipo de alimentação, e a conseqüência é o surgimento deficiência protéica e lesões hepáticas (HIPOLITO, 2003). 
No fígado, existem várias moléculas - glicose estocada como glicogênio e proteínas envolvidas no metabolismo, que podem ser modificadas de acordo com as diferentes dietas. Guyton e Hall (2002) comentam que o fígado, quando apresenta severa disfunção decorrente de várias causas e por dias seguidos, pode levar a um quadro irreversível, com evidente diminuição da taxa do crescimento, e à morte. De acordo com Cotran, Kumar e Collins (2000), o desbalanceamento nutricional pode ser a principal causa de lesão celular. Essas lesões podem ser produzidas ou induzidas pela presença de radicais livres durante o metabolismo de carboidratos, proteínas e lipídios, provocando a fragmentação de proteínas e lipídios nas membranas celulares.

Quanto às rações, embora exista discussão sobre qual é o melhor teor de proteína bruta, a maioria das opiniões situa algo em torno de $40 \%$ como adequado tanto para girinos quanto para a engorda (SEIXAS FILHO et al., 1998). Para os girinos, a origem da proteína animal ou vegetal parece não ter influência, mas sim o teor de proteína bruta na ração (FONTANELLO et al., 1988; MONTEIRO; LIMA; AGOSTINHO, 1988a; 1988b; STÉFANI et al., 1989; STÉFANI; CRIVELENTI, 1992).

Diante do descrito, as rações utilizadas no experimento foram baseadas nos padrões das produzidas para peixes, com a utilização de $40 \%$ de proteína com $4 \%$ de extrato etéreo ou suplementada com óleo de soja. O extrato etéreo consta de extração de lipídeos dos alimentos por meio de lixiviação exaustiva de éter etílico, seguido da remoção do solvente por evaporação. O resíduo seco é constituído por todos os compostos solúveis em solventes orgânicos e insolúveis em água, tais como fosfátidos, esteróides, vitaminas e óleos essenciais, mas não gorduras poliinsaturadas. Já o óleo de soja é rico em gorduras saturadas (palmítico, esteário, oléico) e poliinsaturadas (linoléico e linolênico), que são classificadas como altamente digestivas, proporcionando melhor desempenho aos animais (DALE; FULLER, 1979; SOUZA et al., 2002).
Em relação à proteína, nos grupos-controle $(1 \mathrm{~T}, 2 \mathrm{~T}, 3 \mathrm{~T})$ ocorreu aumento com o passar do tempo de desenvolvimento. $\mathrm{O}$ mesmo se deu nos tratados com dieta suplementada com óleo de soja nas concentrações de 6 e 9\%, nos períodos de 30 e 60 dias de desenvolvimento. Já no período de 90 dias, houve um decréscimo que pode estar associado à troca metabólica e à completa metamorfose pela qual o animal está passando. Ao se observarem os animais com dieta suplementada com $12 \%$ de óleo de soja, verifica-se que diminuíram a concentração no decorrer do desenvolvimento, o que indica a presença de algum estresse metabólico em decorrência do excesso de nutrientes.

O glicogênio pode ser transformado em glicose quando necessário, principalmente se os tecidos necessitarem de energia oxidável. Entretanto, todos os animais precisam ter, nas células, o estoque do glicogênio que indica se um animal é sadio, conforme descrito por Stéfani (1996) e Steiner e colaboradores (2000). Neste trabalho, foi observado que, nos animais com dieta-controle, a formação de glicogênio chega a 3,83 g glicose/ Kg de fígado. No entanto, os animais do grupo submetidos à dieta suplementada com óleo de soja apresentam maior concentração: com 6\%, chegou até 16,3 g glicose/Kg de fígado; com $9 \%$, a 38,9 g glicose $/ \mathrm{Kg}$ de fígado, e com 12\%, a 16,1 g glicose/ Kg de fígado. Os resultados demonstraram que, com $9 \%$, os animais apresentaram o maior estoque de glicogênio, além de equilíbrio na quantidade de proteínas. Até o momento, a dieta com $9 \%$ de óleo de soja foi a melhor opção.

Com relação à quantidade de fenóis, podese observar que os animais do grupo-controle apresentaram aumento, principalmente após 90 dias, o que pode estar correlacionado ao período em que os animais completaram a metamorfose, necessitando de outros metabolismos para seu desenvolvimento, de acordo com Nunes (1998). $\mathrm{O}$ mesmo ocorreu em animais que receberam dieta com $6 \%$ de óleo de soja, mas em concentração menor. Entretanto, nas dietas com 9 e 12\% de óleo de soja, o resultado foi melhor. Isso confir- 
ma o que foi observado em análises histológicas: os fígados de alguns dos animais do grupo-controle e de uma parte tratada com $6 \%$ de óleo de soja tiveram lesões, ampliando a concentração de fenóis, por apresentarem lesões nas células. O mesmo ocorreu com a enzima que catalisa as reações de oxidação, tal como a peroxidase. Foi possível constatar o aumento da atividade enzimática nos animais-controle e nos submetidos a dietas com $6 \%$ de óleo de soja. Nos que passaram por dietas com 9 e $12 \%$ de óleo de soja, o aumento no período de desenvolvimento foi menor do que o dos submetidos a tratamentos-controle e com $6 \%$ de óleo de soja. No entanto, o acréscimo que ocorreu nos grupos 6 e 9 indicou mudança no metabolismo, após completada a metamorfose. Dessa forma, a intensificação de atividade de peroxidase indica maior número de radicais livres, que provocam mais lesões hepáticas, acusando deficiências nutricionais.

Com base nos resultados obtidos, observa-se que deve existir um balanço de nutrientes na dieta que demonstre equilíbrio no metabolismo da rã-touro. Nessas condições, deve-se apresentar as proteínas e suplementar a dieta de óleo de soja, para impedir que o processo nutricional afete o fígado, provocando lesões hepáticas e a conseqüente diminuição de resistência do animal - o que resultará na sua morte ou na diminuição da qualidade e quantidade de sua carne.

\section{Considerações finais}

Neste trabalho, objetivou-se avaliar, por meio de análises bioquímicas, os fígados das rãs-touro submetidas a diferentes dietas experimentais. Os fígados foram analisados em relação à quantidade de proteínas e fenóis totais, à atividade da enzima peroxidase e à concentração do glicogênio.

Os resultados, após comparação com outros esquemas nutricionais e diferentes fórmulas, podem ser usados como indicadores de desenvolvimento nutricional e apontar a presença de estresse oxidativo e de degeneração celular, em decorrência de alterações metabólicas geradas de processos degenerativos ou tóxicos, ocasionados pela dieta à base de ração industrial peletizada, comumente oferecida a rãs-touro criadas em cativeiro com vistas à exploração comercial de sua carne.

O estudo dos parâmetros bioquímicos pode determinar as melhores condições para o desenvolvimento de uma fórmula mais apropriada à dieta, a fim de aumentar a produção de animais para o mercado nacional.

\section{Biochemical aspect in liver of Rana catesbeiana (SHAW, 1802) submitted in different diets}

Biochemical behavior of livers of bull frogs (Rana catesbeiana) submitted to different diets was analyzed. Diets were based on feeds containing protein/lipids. Experimental diets presented $40 \%$ of crude protein $(\mathrm{PB})$ and three different levels quantities of soybean oil (OS) (Treatments: 1) $6 \%$ OS; 2) $9 \%$ OS; 3) $12 \%$ OS). The control diet was commercial feed with $40 \%$ PB and $4 \%$ ether extract. Animals were evaluated on days 30, 60 and 90 of the fattening period. Liver extracts were quantitatively analyzed in relation to total protein, phenols, peroxidase activity and glycogen. Animals that presented increased of concentration of glycogen and protein were those submitted to $9 \%$ OS and $40 \%$ PB diet. This diet led to decreased activity of peroxidase and concentration of phenols. The biochemical analyses can be saw like indicators for the good diet for animals.

Key words: Bullfrog. Liver. Nutrition. Rana catesbeiana.

\section{Referências}

ACADEMIA BRASILEIRA DE ESTUDOS TÉCNICOS EM RANICULTURA. Curso Nutrição e Alimentação em Ranicultura. In: ENCONTRO NACIONAL DE RANICUlTURA, 11., 2001. Bragança Paulista. Anais... Bragança Paulista: Abetra/Ranário Beija-Flor, p. 62-63, 2001. 
BROWN JUNIOR, G. W. The metabolism of amphibia. In: MOORE, J. E. (Ed.). Physiology of the amphibia. 1. ed. Nova York: Academic Press, 1964. v. 1, p. 1-98.

COTRAN, R. S.; KUMAR, V.; COLLINS, T. Robbins. Patologia estrutural e funcional. 6. ed. Rio de Janeiro: Guanabara-Koogan, 2000.

DALE, N. M.; FULLER, H. L. Effects of diet composition on feed intake and growth of chicks under heat estresse. I. Dietary fat level. Poultry Science, Menasha, v. 58, p. 1.529$1.534,1979$.

FONTANELLO, D. et al. Ganho de peso de rã-touro (Rana catesbeiana, Shaw, 1802), criadas em gaiolas individuais de diferentes tamanhos. Boletim do Instituto de Pesca, São Paulo, v. 15, n. 1, p. 45-49, 1988.

GUYTON, A. C.; HALL, J. E. Tratado de fisiologia médica. 10. ed. Rio de Janeiro: Guanabara-Koogan, 2002.

HIPOLITO, M. Deficiência protéica e demais patologias associadas ao fígado de rãs-touro (Rana catesbeiana Shaw, 1802). Boletim do Instituto de Pesca, São Paulo, v. 34, p. 29-33, 2003.

HIPOLITO, M. Prevenção, diagnóstico e tratamento de enfermidades. Revista Brasileira de Agropecuária, São Paulo, v. 1, n. 3, p. 62-69, 1999.

LOWRY, O. H. et al. Protein measurement with the folin phenol reagent. The Journal of Biological Chemistry, Baltimore, v. 193, n. 1, p. 265-275, 1951.

MILLER, G. L. Use of dinitrosalicylic acid reagent for determination of reducing sugar. Analytical Chemistry, Washington, v. 31, n. 3, p. 426-428, 1959.

MOERSCHBACHER, B. M. et al. An elicitor of the hypersensitive lignification response in wheat leaves isolated from the rust fungus Puccinia graminis f. spec. tritici. Zeitschrift für Naturforschung, Tübingen, v. 41, p. 32-37, 1986.

MONTEIRO, E. S.; LIMA, S. L.; AGOSTINHO, C. A. Avaliação de desenvolvimento de rã-touro (Rana catesbeiana Shaw, 1802) alimentadas com diferentes níveis de proteína. In: Reunião Anual da Sociedade Brasileira de Zootecnia, 25., 1988. Viçosa. Anais... Viçosa: SBZ, p. 77, 1988a.

MONTEIRO, E. S.; LIMA, S. L.; AGOSTINHO, C. A. Ensaios de alimentação. II: Influência da terra, proteína de origem animal ou vegetal no desempenho da rãtouro, Rana catesbeiana, Shaw, 1802. In: ENCONTRO NACIONAL DE RANICULTURA, 6., 1988. Rio de Janeiro. Anais... Rio de Janeiro: p. 197-200, 1988b.
NUNES, I. J. Nutrição animal básica. 2. ed. Belo Horizonte: FEP-MVZ, 1998.

RIBEIRO FILHO, O. P. Desempenho e avaliação de carcaça de rã-touro (Rana catesbeiana Shaw, 1802) criada em cativeiro com diferentes níveis de energia metabolizável na ração. 1999. Tese (doutorado em Zootecnia)-Universidade Federal de Viçosa, Viçosa, 1999.

SEIXAS FILHO, J. T. et al. Efeito dos níveis de energia e proteína bruta no desempenho de girinos (Rana catesbeiana, Shaw, 1802). Revista Brasileira de Zootecnia, Viçosa, v. 27, n. 4, p. 664-669, 1998.

SOUTHERTON, S. G.; DEVERALL, B. J. Changes in phenylalanine ammonia-lyase and peroxidase activities in wheat cultivars expressing resistance to the leaf-rust fungus. Plant Pathology, Oxford, v. 39, p. 223-230, 1990.

SOUZA, H. B. A. et al. Efeitos de diferentes fontes de óleo na qualidade da carne de frango. Revista Brasileira de Ciência Avícola, Campinas, v. 4, p. 29, 2002.

STÉFANI, M. V. de. Metabolismo e crescimento de rãtouro (Rana catesbeiana Shaw, 1802) alimentadas com níveis crescente de carboidratos. 1996. Tese (doutorado em Aqüicultura)-Faculdade de Ciências Agrárias e Veterinárias, Universidade Estadual Paulista, Jaboticabal, 1996.

STÉFANI, M. V. de. CARNEIRO, D. J.; DIAS, T. C. R. Exigências protéicas em dietas para girinos de rã-touro, Rana catesbeiana (Shaw, 1802). Ciência Zootécnica, v. 4, n. 1, p. 8-11, 1989.

STÉFANI, M. V. de. CRIVELENTI, G. Níveis protéicos e proporções de proteína de origem animal em dietas artificiais para girinos de rã-touro (Rana catesbeiana Shaw, 1802). In: SIMPÓSIO BRASILEIRO DE AQÜICUlTURA, 7., 1992. Peruíbe. Anais... Peruíbe: Simbraq, p. 183-190, 1992.

STEINER, A. A. et al. The importance of glucose for freezing tolerance/intolerence in the anuran amphibians Bufo paracnemis and Rana catesbeiana. Revista Brasileira de Biologia, Rio de Janeiro, v. 20, n. 2, p. 321-328, 2000.

SWAIN, T.; HILLIS, W. E. The phenolic constituents of Prunus domestica. I. The quantitative analysis of phenolic constituents. Journal of the Science of Food and Agriculture, Hoboken, v. 10, n. 1, p. 63-68, 1959.

Recebido em 13 mar. 2006 / aprovado em 14 jul. 2006

Para referenciar este texto HIPÓLITO, M.; RIBEIRO FILHO, O. P.; BACH, E. E. Aspecto bioquímico em fígados de Rana catesbeiana (SHAW, 1802) submetida a diferentes dietas. ConScientiae Saúde, São Paulo, v. 6, n. 1, p. 49-56, 2007. 